\title{
AS PISTAS GRAMATICAIS DA ARGUMENTAÇÃO
}

\author{
GRAMMATICAL CLUES OF ARGUMENTATION
}

Denise Miotto Mazocco | Lattes | denisemazocco@hotmail.com

Teresa Cristina Wachowicz | Lattes | tecacw@gmail.com

Universidade Federal do Paraná

\begin{abstract}
Resumo: O objetivo deste artigo é realizar um levantamento dos fenômenos gramaticais sintático-semânticos presentes em produções textuais de alunos da Educação Básica (Projeto PIBID Português 2/UFPR). As questões norteadoras centrais são as seguintes: Quais traços gramaticais evidenciam os textos argumentativamente vagos, sem o "projeto do dizer" (POSSENTI, 2002)? E quais evidenciam os textos argumentativamente consistentes e válidos? Em análise de corpus de textos de opinião, coletados no espectro do $6^{\circ}$ ano do Ensino Fundamental II até o $3^{\circ}$ ano do Ensino Médio, verificamos que o que diferencia os textos é uma semântica genérica ou vaga (MÜLLER, 2003) e uma sintaxe de estrutura argumental esvaziada (RAPOSO, 1992), em detrimento de uma semântica específica e estruturas argumentais sintaticamente controladas. Nesse sentido, as construções sintático-semânticas, mais do que recursos de efeito de sentido, passam a ser efetivamente as pistas gramaticais da argumentação.
\end{abstract}

Palavras-chave: Argumentação; Sintaxe; Semântica.

Abstract: The aim of this work is to track down the syntactic-semantic grammatical phenomena present in textual productions of Basic Education students (Projeto PIBID Português 2/UFPR). The central questions are the following: Which grammatical aspects evidence argumentatively vague texts, without the saying purpose (POSSENTI, 2012)? And which of them evidence the argumentatively consistent and valid texts? We analyze opinion texts, made by students from the 6th year of Elementary School II to the 3rd year of High School, and we find that what differentiates the texts is a generic or vague (MÜLLER, 2003) semantics and an empty argument structure syntax (RAPOSO, 1992), in detriment of a specific semantics and syntactically controlled argument structures. In this sense, syntactic-semantic constructs, rather than meaning-effect resources, effectively become the grammatical clues of argumentation.

Keywords: Argumentation; Syntax; Semantics. 


\section{Introdução}

Tanto as orientações curriculares nacionais quanto os estudos de linguística de texto e/ ou discurso aplicada ao ensino de língua materna delimitam o texto (oral ou escrito) como objetivo didático ou unidade de análise. No entanto, o papel da "análise linguística" fica subjacente a esse objetivo, exercendo uma espécie de "suporte" de intenções vagas da estrutura discursivo-textual.

Um trecho da Base Nacional Comum Curricular (BNCC) das orientações para o Ensino Médio, por exemplo, restringe explicitamente as unidades gramaticais - esparsamente citadas - à microestrutura do texto:

Espera-se que os/as estudantes, atentos a escolhas linguístico-discursivas, (...) avaliem escolhas de natureza microestrutural (como a utilização de determinado tempo verbal, de uma construção na voz passiva, de uma representação metafórica etc.) e seus efeitos de sentido. (BRASIL, 2016, p. 510).

Se há microestrutura, há macroestrutura (gêneros e tipologias diversas) e contexto de produção (discursos ideológicos em vozes sociais). Logo, há um vetor 'discurso $\rightarrow$ texto $\rightarrow$ língua/gramática', já canonicamente estabelecido, que intercondiciona os três níveis da produção da linguagem. É certo que os três níveis têm construções autônomas, podendo ser analisados em suas próprias condições (sociais, disposicionais e estruturais). A tríade, aliás, já era sistematizada como partes da retórica aristotélica, traduzidas em inventio, dispositio e elocutio, ao lado de memoria e oratoria (REBOUL, 1998, p. 43), ou então recuperada por Bakhtin, nos elementos tema, composição e estilo, constituidores dos gêneros do discurso (BAKHTIN, 1992).

No entanto, a grande questão que sucede hoje, no ensino de língua, diz respeito ao modo como sistematizar a relação: Seria a gramática apenas um recurso de construção de estilo e efeito de sentido? Não poderíamos explorar a gramática como sendo uma unidade de análise indicadora de opções textuais e discursivas, como locus de pistas que indicam, inclusive, construção argumentativa?

De outro viés, a linguística brasileira do texto e discurso desde a década de 1970 recondiciona propostas de tratamento textual, que igualmente alocam "análise linguística" no estatuto de recursos expressivos. Geraldi (1991, p. 190-191), por exemplo, comenta sobre o papel da atividade metalinguística:

Considero as atividades metalingüísticas como uma reflexão analítica sobre os recursos expressivos, que levam à construção de noções com as 
quais se torna possível categorizar tais recursos. Assim, essas atividades produzem uma linguagem (a metalinguagem) mais ou menos coerente que permite falar sobre a linguagem, seu funcionamento, as configurações textuais e, no interior destas, o léxico, as estruturas morfossintáticas e entoacionais.

Bom, as categorias gramaticais já estão em análise há séculos. Só para pinçar um período histórico significativamente distante, os estoicistas (por volta de 300 a.C.) já levantavam a oposição forma e sentido, retomada por Saussure na dicotomia significante e significado, e tratavam de modo separado os módulos da fonética, gramática e etimologia (ROBINS, 1983). Quanto às categorias morfossintáticas, as protogramáticas tradicionais clássicas de Dionísio da Trácia (100 a.C.) e Prisciano (500 d.C.), dentre outros pensadores, investigavam a rica morfologia de caso do grego e latim, respectivamente, para descrever as relações entre nome e verbo, e de ambos com as outras classes de palavras (KOERNER; ASCHER, 1995).

Tradicionalmente, sabe-se que a gramática surge como conteúdo propedêutico da retórica, no trivium das artes humanas nomeado por Boécio ( \pm 500 d.C.) como dialética, retórica e gramática. Esse conteúdo gramatical esteve mesclado à tradição da filosofia da linguagem desde o seu surgimento, ganhando corpo de reflexão empírica e teórica que hoje se rotula como fonética/fonologia, morfologia, sintaxe e semântica, compondo o conteúdo formal da grande área da linguística.

Logo, as unidades gramaticais não se limitam à - nem se definem pela - sua função textual de construção de sentido discursivo. Mas se a gramática nos oferece uma tradição secular de análise, como relacioná-la - hoje - a traços argumentativos dos textos dos alunos?

A partir das questões esboçadas acima, e justificadas historicamente, nosso objetivo neste artigo é relacionar categorias gramaticais relativas à semântica e à sintaxe, especificamente, que podem funcionar como pistas para construções argumentativas - para o bem ou para o mal. Assim, a análise linguística proposta aqui toma a gramática como um locus de opções textuais argumentativas, mais do que recursos isolados de efeitos expressivos. Nossas hipóteses, grosso modo, revelam uma semântica do significado genérico e vago, bem como uma sintaxe de estrutura argumental esvaziada, recorrente em textos 'fracos'; por outro lado, os textos 'fortes' concentram referências específicas e concretas, em paralelo ao domínio do bloco informacional argumental da estrutura sintática. Se 
Pécora (1992) levanta o diagnóstico do argumento "lugar-comum" dos textos "fracos", nós defendemos que há traços gramaticais (sintático-semânticos)que também os caracterizam. Por outro lado, também revertemos a análise de Lemos (1977) da estratégia de esvaziamento sintático-semântico desses textos problemáticos.

Nesse sentido, o artigo se organiza da seguinte maneira: A Seção 1 esboçará a análise sintático-semântica da gramática de textos argumentativamente fracos; a Seção 2 apresentará traços de mesmo critério nos textos argumentativamente fortes. Os textos analisados foram coletados no corpus de textos de opinião, no espectro do $6^{\circ}$ ano do Ensino Fundamental II até o $3^{\circ}$ ano do Ensino Médio, do Projeto PIBID Português 2/UFPR. Nas considerações finais, retornaremos às orientações curriculares, para delinear um caminho para o tratamento da gramática no ensino.

\section{A gramática do texto argumentativamente 'fraco'}

Muitos trabalhos no começo da década de 1990 propõem-se a analisar textos escolares e apresentar diagnósticos de seus problemas sob diferentes critérios. Pécora (1992) elenca 13 problemas de corpora anteriores e posteriores ao vestibular: 1. acentuação, 2. pontuação, 3. ortografia, 4. norma culta, 5. emprego lexical, 6. incompletude associativa, 7. emprego de relatores, 8. emprego de anafóricos, 9. redundância, 10. noções confusas, 11. noções de totalidade indeterminada, 12. noções semiformalizadas, e 13. noções de lugar-comum. Os quatro primeiros são da ordem da apreensão da convenção escrita da norma padrão; os problemas de 5 a 9 são da ordem da coesão textual; e os últimos são da ordem da argumentação. Na conclusão do autor, todos eles aglomeram-se no problema central de uma tentativa por parte dos alunos de reprodução dos "moldes fornecidos pelo figurino oficial” (PÉCORA, 1992, p. 118).

A relação de distanciamento do aluno diante de seu texto, revelada pelo empréstimo inconsciente do "figurino oficial", tem um fundo moral. Bernardo (1991) historiciza e ilustra a dicotomia maniqueísta ocidental do bem e do mal, do dedutivo e do indutivo, que as sociedades hierarquizantes incorporam para manter alunos quietos, no lugar de inquietos. O aluno inquieto controla a dialética, consegue partir do indutivo para o dedutivo; o quieto não faz opção por caminho algum. Isso é um problema moral. Escrever para fazer diferença significa subir paredes da caverna platônica e enxergar para além da moral estabelecida, transpor em estilo eleito a gramática: 
Redação, enquanto redação, tem muito a ver com coragem. O texto que se pretenda propriamente ético se define pelo grau da sua resistência. Insistir em pensar, insistir em externar o pensado, insistir em certas conclusões para imprimi-las a fogo sobre o mundo, implica o simultâneo ato de resistir àqueles que se alimentam da mudez alheia. Isto é, resistir sem concessões à censura, qualquer que seja o seu tipo, qualquer que seja sua fonte. (BERNARDO, 1991, p. 165).

Por outro lado, há diagnósticos essencialmente textuais. Costa Val (1991), na base dos sete fatores sociocognitivos de textualidade de Beaugrande e Dressler (1983) - intencionalidade, aceitabilidade, informatividade, situcionalidade, intertextualidade, coerência e coesão -, aponta os problemas das redações de vestibular:

As redações, em sua maioria, apresentam um arcabouço formal e conceitual aceitável. Configuram-se como todos completos, dotados de continuidade e progressão. Mantêm certa lógica interna e se organizam conforme modelo previsto para dissertações, além de exibirem nível satisfatório de correção gramatical. Entretanto, a impressão que se tem após sua leitura é que se trata de maus textos, pobres, simplistas, insípidos, quase todos iguais, muitos deles eivados de impropriedades. São textos que não agradam, não convencem, não entusiasmam. (COSTA VAL, 1991, p. 118).

Para além dos comentários sobre os textos "fracos", e evidentemente pressupondo as questões morais escolares que contaminam o ensino de língua em nossas escolas, a questão que colocamos aqui diz respeito aos traços gramaticais desses problemas. Especificamente, qual é a semântica e a sintaxe de textos com as "noções confusas", de Pécora? E qual seria a gramática do texto “insípido”, de Costa Val?

Para introduzir um primeiro exemplo de texto às nossas análises, os bolsistas do Programa Institucional de Bolsas de Iniciação à Docência (PIBID), do subprojeto Letras/ Português 2, da Universidade Federal do Paraná (UFPR), intitulado "Argumentação e ensino de Língua Portuguesa”, aplicaram a proposta de produção de texto opinativo a alunos do Ensino Médio de um colégio estadual de Curitiba, durante o período de ocupações das escolas, em protesto contra a reforma do Ensino Médio proposta pelo governo Temer. Isso aconteceu no segundo semestre de 2016. Segue o texto com as anotações dos bolsistas para a prática de reescrita: 
Figura 1. Texto 1: Opinativo sobre a reforma do Ensino Médio, 3․ EM, coleta PIBID Português 2/UFPR As umediad paro um Emsino medio melhor

$\mathrm{com}$ a medida prorisória substifun r for undonces que vâo mehorar is unsino médio, uma colos í caumentando itremps de coula

Quctra unedida que vajudarà imito í a que vai pazer ar que las uscolas passem o lásico que vai verar, e pensondo no futuro, $\theta$ vesto do tempo fará que s contéido que rerá passo. do seja com base no que o caluno vaitra. vearhar.

Essas medidas ajudam oos forcens paraque nais prexcisem estudar toncos materias que nöor seráa utilizodo. ISUBSTituA

Clunos protustom contra essas medidos, porém umitos nö sobem dirico sokerelas i protes tom para que percom vaula

1. Explique $\theta$ que é a medida provisória, quais os pontes positives e negatives desta medida.

2. Socé é a faver av centra a medida proviréria

Primeiramente, observamos que, como unidade de significado, o texto não se mantém, pois, por exemplo, "a medida provisória” ou "o básico" não ganham detalhamento explicativo. Além disso, as construções nominais do texto parecem acompanhar uma tendência ao significado genérico: "Mudanças" aparece como um plural sem determinante e sem modificador, e acontece o mesmo com "alunos" e "matérias". O singular sem determinante, ou singular nu (OLIVEIRA; PERUCHI MEZARI, 2012) também contribui: 
"aula". Outras estruturas de interpretação genérica aparecem em nominais com determinante ("as escolas", "o básico", ou "o conteúdo que será passado").

Müller (2003, p. 153) define generecidade como a significação "de regularidades ou leis mais gerais”. Nesse sentido, uma expressão é genérica se valer como verdade para o conjunto de indivíduos denotado por ela, mesmo que um indivíduo seja exceção. A sentença "Leão tem juba", por exemplo, tem significado genérico e vale para todos os leões do mundo. Mas se um leão nascer com alguma anomalia genética que lhe cause a ausência de juba, a sentença não precisa ser falseada necessariamente.

A genericidade pode ser construída de duas maneiras: 1) expressões de referência a espécies, em que a estrutura nominal mantém o valor genérico (exemplos (1) a (5), da autora); e 2) sentenças genericamente quantificadas, em que um quantificador genérico (todo/s, qualquer, por exemplo) faz a leitura ((6) e (7)):

(1) O café chegou ao Brasil em 1990.

(2) As cobras são animais perigosos.

(3) Um corpo atrai outro com uma força que varia na razão inversa do quadrado de suas distâncias.

(4) Brasileiro gosta de arroz e feijão.

(5) Professores trabalham muito.

(6) Todas as cobras são perigosas.

(7) Todos os professores trabalham muito.

Vale observar que a maioria das sentenças está no tempo presente simples, o que facilita composicionalmente o significado das regularidades e leis. Mas a exceção está na sentença (1), no passado perfeito, que igualmente refere um evento de referência vaga, pois a denotação de espécie de "o café" mantém o sentido genérico. Ou seja, não se trata de um saco específico de café, ou de um lote de mudas registrado, e sim de uma espécie de planta/semente/bebida que nomeia um conjunto genérico.

Ora, o texto do aluno secundarista (Figura 1) está repleto de referências genéricas mantidas por expressões nominais. Mas o objetivo não era descrever leis e regularidades presentes no mundo. Talvez em um texto de apresentação da Medida Provisória, em que se objetivasse descrever a situação atual do Ensino Médio no Brasil, as situações recorrentes e gerais seriam focadas. Entretanto, o texto em tela é argumentativo. Nesse movimento, prevêem-se macroposições abstratas e cognitivamente operadas que sustentam a prova de uma tese. Em Adam (2004, 2008), seguindo as bases de Toulmin (2006), as macroposições argumentativas poderiam didaticamente ser assim representadas: 
Figura 2. Esquema argumentativo

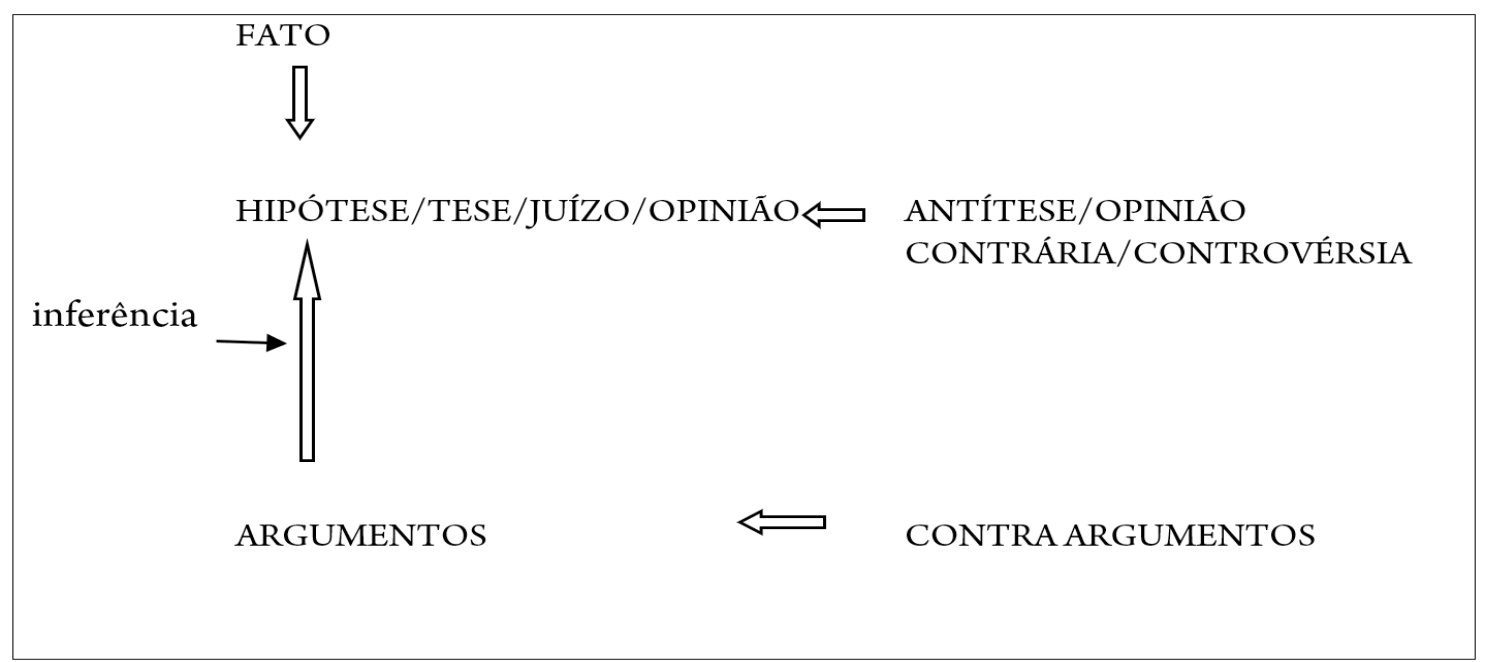

Fonte: $\operatorname{ADAM}(2004,2008)$

O texto do aluno (Figura 1), no exercício de abstração que requer o princípio de interpretabilidade (CHAROLLES, 1989), segundo o qual todo texto faz um mínimo de sentido, de fato traz pistas de construção argumentativa. Há um fato (a medida provisória) sobre o qual se aplica um juízo (vai melhorar), sustentado por argumentos (o tempo de aula que vai aumentar, o conteúdo direcionado ao trabalho no futuro, o excesso de matérias inúteis). Há mesmo o esboço da contra-argumentação (o último parágrafo).

Contudo, o seu problema é a falta de referencialidade no mundo, que contribuiria a um controle dos eventos e fatos envolvidos no fio argumentativo. Para o propósito textual, portanto, a semântica genérica enfraquece a argumentação. É essa semântica genérica que talvez justifique as categorias intuitivas das "noções confusas" ou de "totalidade indeterminada”, de Pécora (1992).

Outro traço marcante do texto verifica-se no esvaziamento sintático de algumas estruturas. Nos primeiro e segundo parágrafos, as perífrases verbais "vai fazer mudanças que..." e "o básico que vai usar..., respectivamente, têm esvaziamento em suas estruturas transitivas, que, na tradição da semântica lexical, paralela à sintaxe gerativa, ganha o nome de "estrutura argumental". O verbo, enquanto núcleo do sintagma, tem as posições de sujeito e complemento, genericamente chamadas de argumentos. Uma estrutura argumental é uma "entidade estritamente sintática, nomeadamente a informação que especifica como os argumentos de um verbo são codificados na sintaxe"1 (PINKER, 1989, p. 71). Raposo (1992, p. 91) prediz que:

\footnotetext{
1 "I use the term 'argument structure' to refer to a strictly syntactic entity, mamely the information that specifies how a verb's arguments are encoded in the syntax".
} 
[...] as expressões lingüísticas podem ser analisadas num predicador central e num determinado número de argumentos que lhe completam o sentido, convertendo o predicador numa expressão semanticamente completa. Na estrutura da oração, os argumentos de um predicador verbal correspondem ao sujeito e aos complementos subcategorizados pelo predicador.

Logo, não só os verbos, mas qualquer núcleo lexical de projeção XP ou X” (em que X é uma variável de verbo, substantivo, adjetivo e advérbio), como no esboço simplificado a seguir do modelo Princípios e Parâmetros da Gramática Gerativa (MIOTO; FIGUEIREDO SILVA; LOPES, 2005, p. 47), podem predicar e ser preenchidos por argumentos (especificador e complemento).

Figura 3. Modelo genérico da estrutura X”, XP ou X-barra

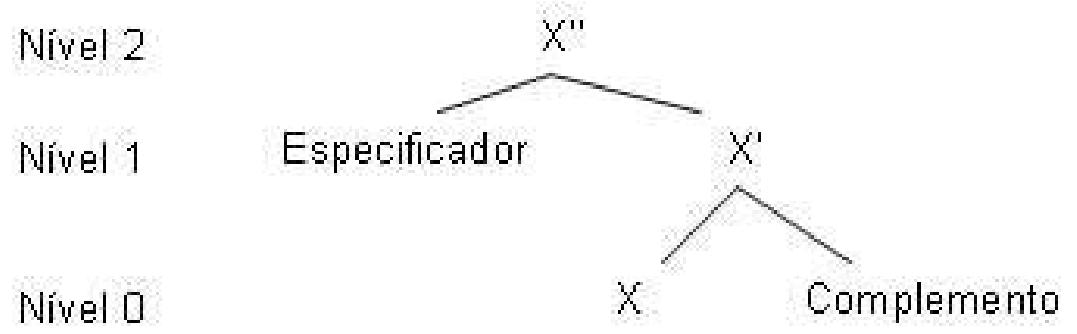

Fonte: MIOTO; FIGUEIREDO SILVA; LOPES (2005, p. 47)

No texto do aluno (Figura 1), as estruturas "vai fazer mudanças que..." e "o básico que vai usar...” estão sem sujeito (especificador). A inferência do olhar de professor poderia dizer que esses sujeitos estão subentendidos num tema cujas informações o aluno trouxe provavelmente da discussão prévia em sala, ou mesmo da situação política marcante e violenta contra as ocupações das escolas públicas nesse período. O problema é que o texto não encerra o significado na unidade argumentativa que lhe cabe. $O$ esvaziamento sintático justifica os textos "pobres, eivados de impropriedades" a que se refere também intuitivamente Costa Val (1991).

Um segundo exemplo foi coletado no $8^{\circ}$ ano do Ensino Fundamental II, nos trabalhos do mesmo subprojeto PIBID. Os traços de uma semântica genérica e de uma sintaxe esvaziada são igualmente verificados: "a sociedade que estamos" e "agressão" (de quem para quem?). A recorrência nos permite apontar para uma estrutura gramatical a ser trabalhada em reescrita: 
Figura 4. Texto 2: Opinativo sobre violência, $8^{\circ}$ ano EF, com anotações para a reescrita

VERSÃO DEFINITIVA

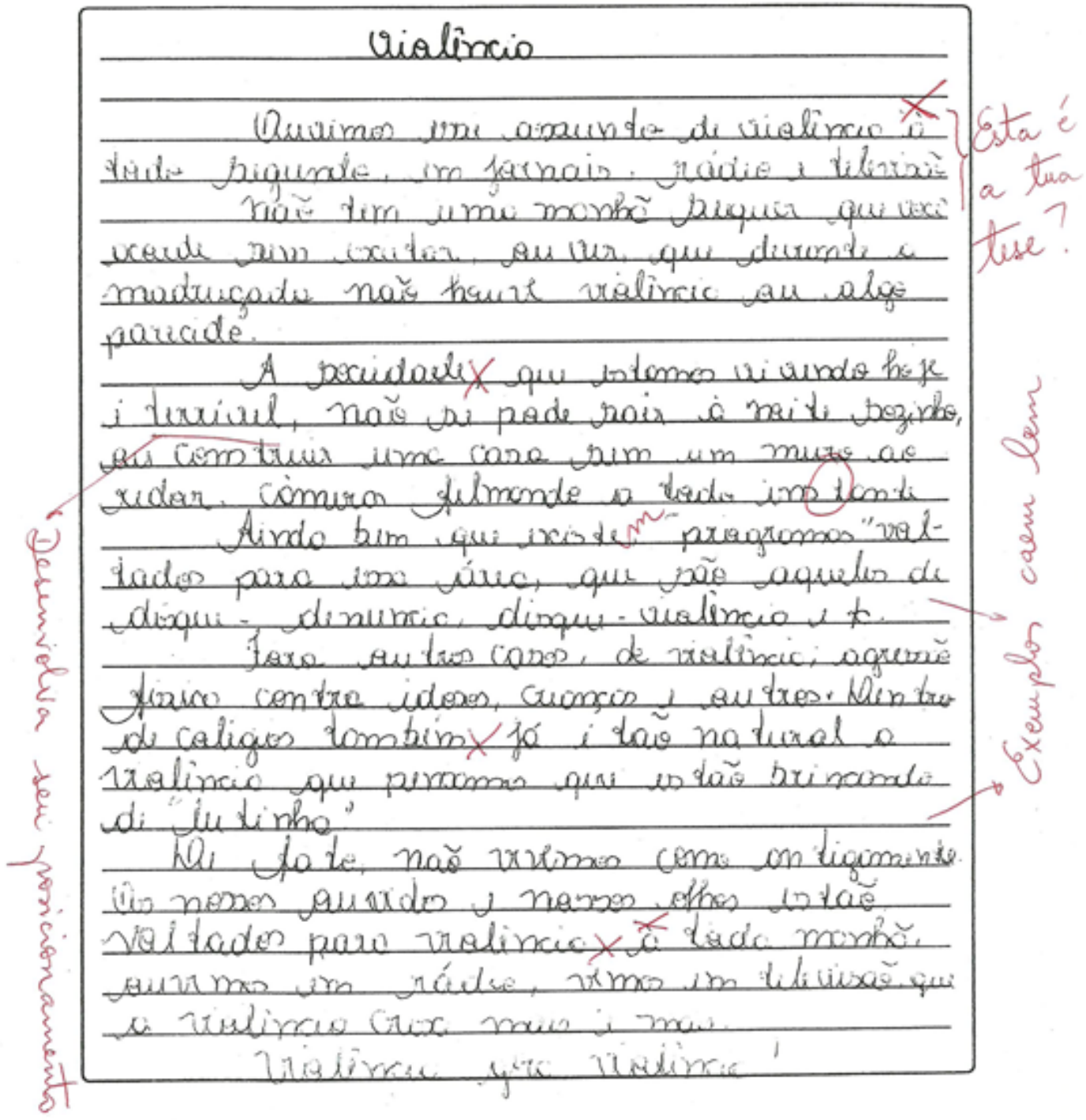

O problema textual aqui é que a argumentação está mais camuflada. Em análise coletiva com os bolsistas, chegamos a desenvolver uma questão: "Será que o texto tenta construir timidamente argumentos, ou ele patina na genericidade de uma descrição caótica de um estado de coisas?” Tendemos à segunda possibilidade, dada a falta de referência a fatos concretos que desenvolveriam argumentos concretos.

Há mais um tipo de construção muito recorrente nesses textos: a construção de escalas abertas em que uma semântica de vagueza não ganha espectro definido. Ao final do texto, a sentença "a violência cresce mais e mais" evidencia escala aberta. Outras expressões típicas, que os colegas professores podem confirmar: "cada vez mais..., "desde os primórdios...", "a violência vem aumentando a cada dia...” etc. 
O conceito de escala, na semântica, vem para explicar o significado de medida gradual de algumas expressões, centradamente adjetivos e advérbios. O verbo 'escurecer', por exemplo, deriva de um adjetivo (escuro) que tem escala aberta, de natureza vaga; por outro lado, o verbo 'entortar' deriva de um adjetivo (torto) que tem escala fechada, com resultado definido. As noções de 'grau' e 'dimensão' são a base para a definição de 'escala':

[...] adjetivos graduais mapeiam seus argumentos em representações abstratas da medida, ou do GRAU, que são formalizados como pontos ou intervalos parcialmente ordenados em alguma DIMENSÃO (por exemplo, altura, preço, peso, e outros). O conjunto de graus ordenados correspondem a uma escala ${ }^{2}$ [...]. (KENNEDY; MCNALLY, 2005, p. 349).

Nos textos argumentativamente fracos apresentados acima, a semântica genérica das expressões nominais e as pressuposições escalares vagas dos advérbios, em parceria com o esvaziamento sintático - tanto de especificador quanto de complemento -, revelam um diagnóstico mais preciso dos problemas gramaticais recorrentes nos textos escolares que atingem diretamente a sua força argumentativa. No olhar mais finamente filosófico de Bernardo (1991), o aluno está engessado numa moral que não lhe condiciona ao olhar crítico sobre os fatos concretos do mundo, como se ele estivesse deslegitimado a escrever algo significativo no espaço em branco do papel. Há pistas gramaticais dessa concepção atravessada de texto.

\section{A gramática do texto argumentativamente 'forte'}

Sírio Possenti, em um texto basilar sobre textos de vestibular, analisa um traço determinante no que consideramos texto 'bom', ou argumentativamente 'forte': sua autoria. E autoria se definiria como a habilidade de saber como dar voz aos outros e a sua própria voz:

[...] [afirmei anteriormente que] um dos indícios de autoria é dar voz aos outros. Mas também disse que um texto bom é uma questão de como... Podemos juntar as duas coisas: pode ser uma questão de como dar voz aos outros. Em princípio, como regra, pode-se sugerir "nada de mesmice", nada de empregar apenas o verbo "colocar" ou o menos marcado "dizer". A variação é de bom tom. Mas, de novo, não se trata de variar por variar, de organizar uma lista de verbos dicendi e prometer não empregar o mesmo verbo mais de uma vez em cada texto. A variação só é interessante quando obedece a tomadas de posição ou se faz sentido de outra forma. (POSSENTI, 2002, p. 123).

Intuitivamente, o texto abaixo é considerado um texto 'bom'. Trata-se de uma produção de um aluno do segundo ano do Ensino Médio, realizada após uma aula sobre

2 “...gradable adjectives map their arguments onto abstract representations of measurement, or DEGREES, which are formalized as points or intervals partially ordered along some DIMENSION (e.g. height, cost, weight, and so forth $[\ldots])$. The set of ordered degrees corresponds to a SCALE [...].” 
argumentação. Esse texto se sobressaiu à média das produções dos demais alunos, dado o domínio da tipologia textual e das marcas discursivas do controle das vozes. Mas, para além disso, vamos tentar evidenciar uma semântica e uma sintaxe que corroboram à autoria:

Figura 5. Texto 3: Opinativo sobre o Estatuto da Família, $2^{\circ}$ ano EM Em defESA de tODAs as famícias

A câmara dos dóputados aprovou em 2015 o "Estatuto da Família", cuso obje: tivo é definir familia como sendo areinas aquele grupo en que itá uma união estável ENTRE HOMEM E MULHER, EXCLVINDO QUALQUER OUTRO TIPO FORMAÇÃO FAMILIAR qUE não englobe the uniãe. Analisando as informageö́s das quais dispomos sobres as

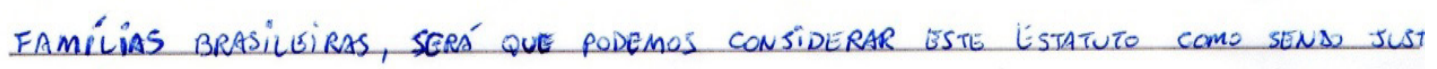
- Conso rabizado em 2010 demonstra que havia na época, no Breasiza

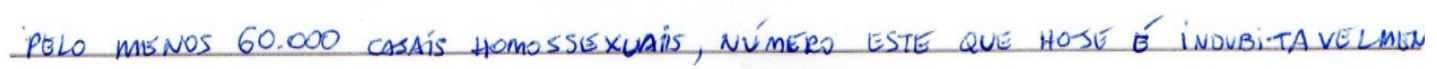
IE maior, Visto que houve, no ano seguinte A PESquísa, a libiraģão da união géstávir para eassis homosséxuais no país. Sama-se ainda, aos casais homoafetiv

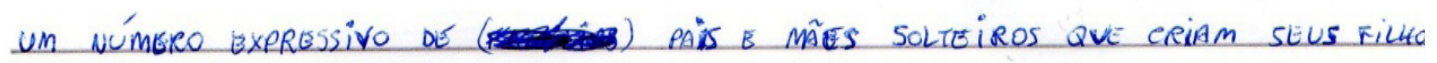
sozinitos ou junto a outro parente que näo Í seU parctiro afetivo. Logo, a decisão da câmara excluirá uma significativa parcela destós grupos famicii ress de sua definisão, ignorando os lagos afetivos existéntes entre as pessoas E as mudangas pelas quais as famílias passtram através dos sí́culos lom moio à Sociedatis. Já não vivímos da mesma forma eÉm que nossos avós viveram,

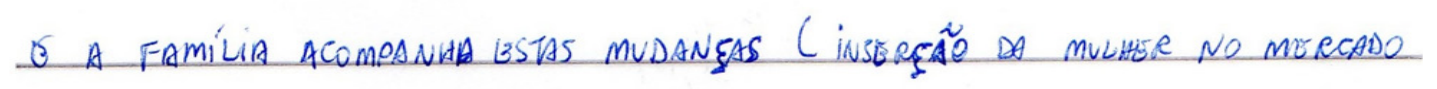
de trabalho, direitos conquistados por casais homoafetivos, dentre várias outras). Outro ponto muito importante a ser notado ú a rigliciosidader com a quk se exprerssam os apoiadoriss a proposta. Como bim disse a desputada Mrria de

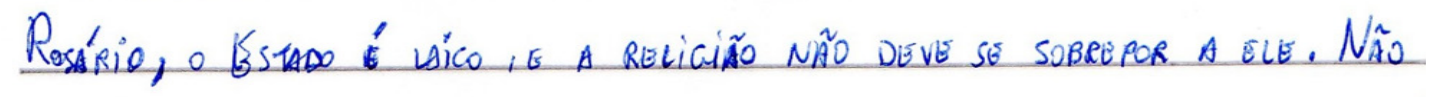

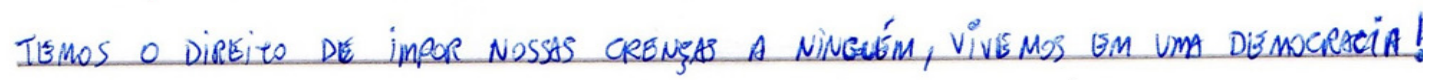

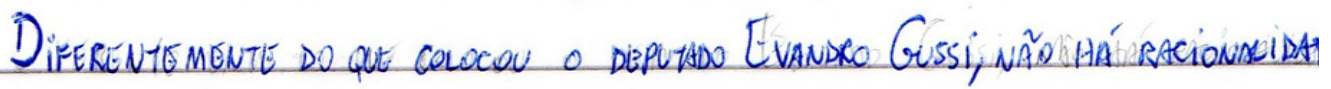

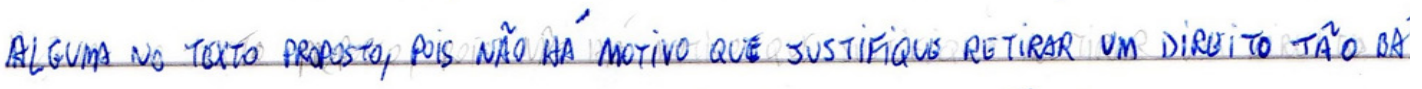

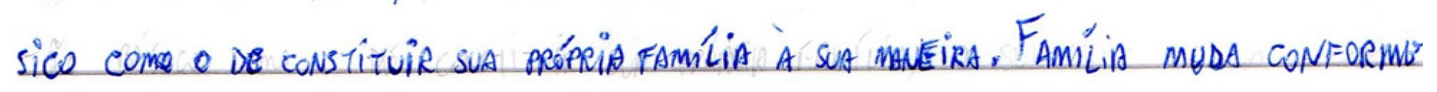

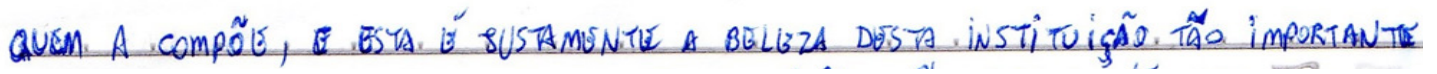


A autoria do texto acima revela-se em vários traços, mas como propõe Possenti (2002), a maneira como se controlam as vozes coatua com a construção da voz do autor. O uso das aspas logo na primeira linha, bem como os verbos dicendi nos últimos parágrafos ("disse", "colocou”), na função de chamar à presença no texto as vozes da controvérsia argumentativa evidenciam o controle de quem está ao lado da tese (a deputada Maria do Rosário) e de quem está ao lado da antítese (o deputado Evandro Gussi). Esse controle também é garantido com o emprego de advérbios, como 'bem' e 'diferentemente'.

Seguindo o esquema argumentativo de Adam $(1992,2008)$ da Figura 2, acima, o fato sobre o qual se construirá a argumentação está no primeiro parágrafo. Ao contrário do texto 2 (Figura 4), ele está especificado. A pergunta retórica em seu desfecho ("Será que podemos considerar este estatuto como sendo justo?") anuncia a tese, melhor explicitada no último parágrafo. O segundo parágrafo constrói um argumento de causa e consequência - construído com a conclusiva introduzida pelo conector 'logo' -, ao passo que o terceiro argumenta pela essência da legislação, para depois dissociar as noções de estado e religião (FIORIN, 2015).

Comparativamente aos textos definidos como argumentativamente "fracos", da seção anterior, este caminha semântica e sintaticamente no sentido oposto. As expressões nominais ganham referencialidade no mundo, imprimindo ao texto a habilidade de leitura crítica de acontecimentos concretos.

Segundo Lyons (1977, p. 149), seguido de uma série de manuais de semântica que o utilizam sob o mesmo objetivo (SAEED, 2005; CANÇADO, 2012, dentre outros), as expressões referenciais são sintaticamente de três categorias: nomes próprios, pronomes pessoais e descrições definidas:

\begin{abstract}
Os sintagmas nominais definidos foram classificados por Russell (1905) como descrições definidas. O termo 'descrição definida' liga-se ao facto de podermos identificar um referente, não só nomeando-o, mas também fornecendo ao auditor ou leitor uma descrição suficientemente pormenorizada, no contexto do enunciado particular, que permite distingui-lo de todos os outros indivíduos no universo do discurso. Por exemplo, 'o homem alto ali à frente', num contexto de enunciação dado, pode ser usado como uma descrição definida identificando um único referente. ${ }^{3}$
\end{abstract}

Assim, a cadeia referencial presente no texto - o "Estatuto da Família” (1 1 parágrafo $\rightarrow$ a decisão da câmara ( $2^{\circ}$ parágrafo $) \rightarrow$ a proposta ( $3^{\circ}$ parágrafo $) \rightarrow$ o texto pro-

\footnotetext{
${ }^{3}$ Lyons (1977) é uma edição portuguesa. Não precisa, portanto, de tradução.
} 
posto ( $4^{\circ}$ parágrafo) - constrói a manutenção temática e a referencialidade concreta do texto. As expressões de semântica genérica - "homem”, "mulher", "casais homossexuais", "a religião" etc. - ganham ancoragem no trato concreto da proposta do estatuto, sustentado também pelos nomes próprios portadores das vozes ideológicas do texto. Ou seja, a semântica genérica não dá aqui conteúdo vago aos fatos referidos. Ao contrário, neles se constrói e se mantém.

Além disso, ainda na referencialidade, as expressões dêiticas, como "este Estatuto" no primeiro parágrafo e "destes grupos familiares" no segundo parágrafo, recuperam um referente bem construído no texto. Em outras palavras, o leitor compreende que se trata do Estatuto da Família e das configurações familiares citadas anteriormente, respectivamente. Ao contrário, por exemplo, do "dessa área”, no quarto parágrafo do segundo texto, cujo referente é difícil de se recuperar anaforicamente. O leitor pode entender que a referência é às medidas de segurança (muros nas casas, câmeras) ou à violência de um modo geral.

Do ponto de vista sintático, as estruturas argumentais ganham preenchimento e algumas sentenças relativas e complementos preposicionados: "as informações das quais dispomos sobre as famílias brasileiras" ( $1^{\circ}$ parágrafo); "as mudanças pelas quais as famílias passaram através dos séculos em meio à sociedade" ( $2^{\circ}$ parágrafo); "a formação de nossa sociedade" ( $4^{\circ}$ parágrafo). Além disso, uma oração conformativa ("Como bem disse a deputada Maria do Rosário") e outra adverbial ("Diferentemente do que colocou o deputado Evandro Gussi”), não só introduzem uma informação veiculada na sentença principal, mas também incluem o posicionamento da autora sobre essa informação. Outro ponto, são as sentenças adjuntas introduzidas pelo gerúndio "excluindo", no primeiro parágrafo, e "ignorando", no segundo parágrafo, que, além de comporem uma estrutura paralelística no mínimo interessante, encaminham a tese do autor, nesse caso.

O uso recorrente da primeira pessoa do plural (nós), em seus desdobramentos pronominais, no lugar de impessoalizar o texto, traz novamente à presença o próprio leitor, evidenciando o domínio de uma figura de linguagem que ata a interlocução à mesma causa ideológica.

Tudo isso evidencia como a estrutura sintática e a semântica estão bem amarradas à construção da tipologia textual. É a sentença adjunta, por exemplo, que, ao introduzir as falas dos deputados, os transforma em argumento e contra-argumento.

Logo, para além do controle de vozes, o texto argumentativamente forte, como o acima, atrela à autoria o controle semântico e sintático sobre a construção argumentativa. O esvaziamento gramatical explicitado na seção anterior agora ganha referencialidade semântica e preenchimento sintático. Vale a pena considerar que um texto argumentati- 
vamente forte não aparece apenas no Ensino Médio. Dolz (1996, p. 230) defende que a argumentação pode ser explorada desde as séries iniciais:

Uma pesquisa recente sobre os manuais utilizados na Suíça de língua francesa chamou a nossa atenção para a completa falta de textos argumentativos com uma dimensão dialógica e compreendendo contraargumentos, bem como a ausência de textos de opinião simplesmente expondo o ponto de vista de um único autor em uma questão específica. No entanto, uma ação na escola centrada na compreensão e produção de textos argumentativos parece viável mesmo na escola primária (cf. Brassart, 1988, 1990). ${ }^{4}$

Um exemplo segue abaixo:

Figura 6. Texto 4: Opinativo sobre internet, $6^{\circ}$ ano EF

Escreva um texto de até 20 linhas dando a sua opinião sobre o uso da internet (redes sociais, sites de busca, jogos, entre outros). Você pode utilizar exemplos para deixar sua opinião mais forte. Não se esqueça de colocar o título!

Opimiaes da internat

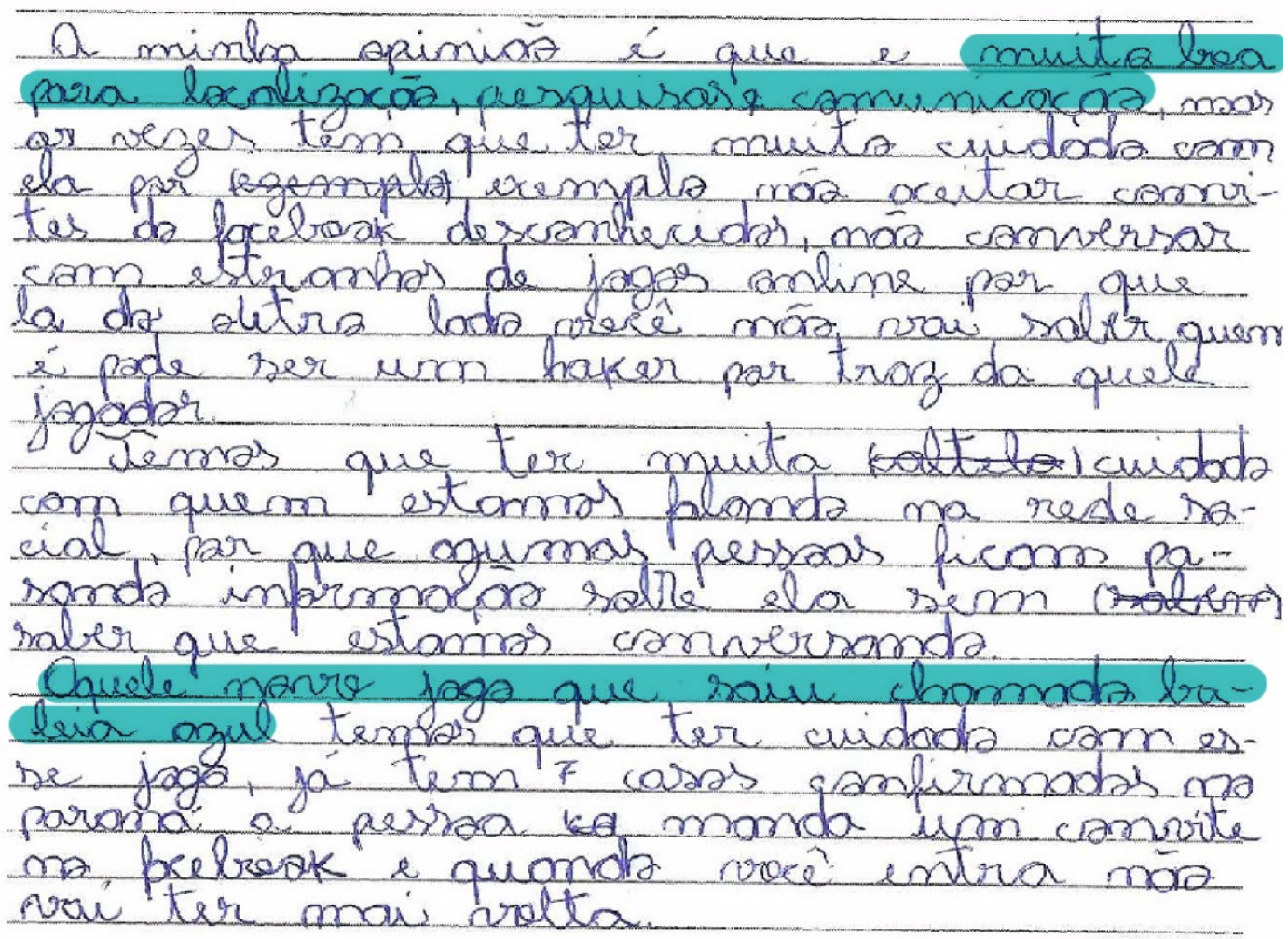

\footnotetext{
4 "A recent inquiry concerning the handbooks used in French speaking Switzerland, brought to our attention the complete lack of argumentative texts having a dialogical dimension and comprising counterarguments, as well as the absence of opinion texts simply exposing the point of view of a single author on one particular issue. Yet, an action in school centred on the understanding and production of argumentative texts seems feasible even in primary school (cf. Brassart, 1988, 1990).”
} 
Esse texto apresenta a estrutura argumentativa esperada: com tese - a internet é boa, mas é preciso ter cuidado ao utilizá-la - e argumentos - a conversa com pessoas desconhecidas e o exemplo do jogo. Quanto às questões sintático-semânticas, podemos dizer que o aluno está no caminho para o que é esperado de um texto forte; ou seja, ao mesmo tempo em que, por exemplo, falta o termo "internet" para ser referenciado no primeiro parágrafo - está apenas no título -, no último parágrafo há o nome do jogo 'baleia azul', que introduz um exemplo específico. Além disso, o aluno já emprega conjunções argumentativas, como o "mas" (primeiro parágrafo) e "por que" (segundo parágrafo). Obviamente, há "erros" (considerando a escrita padrão) de concordância, grafia, etc.; mas, apesar disso, o que queremos mostrar aqui é que alunos do Ensino Fundamental já têm condições de desenvolver textos argumentativos fortes.

\section{Considerações finais}

Com as análises desenvolvidas acima, tivemos a intenção de provar uma gramática dos textos dos alunos que não se limita a "recursos expressivos de efeito de sentido", como preveem orientações curriculares ou algumas análises discursivas e/ou diagnósticas. Ao contrário, ela parece sustentar efetivamente tipologia textual, pelo menos a argumentativa, que foi o recorte de nosso estudo.

Nesse papel, há sinalizações da semântica e da sintaxe esvaziadas nos textos "fracos", ao passo que os textos "fortes" ganham com semântica referencial específica, incluindo cadeias anafóricas, junto a uma sintaxe de estrutura argumental preenchida.

Os termos empregados na formulação de nossa hipótese lembram uma tese clássica dos anos 1970 sobre os textos ruins. Lemos (1977) defende que o aluno desenvolve estratégias de preenchimento do espaço em branco do papel como alternativa para escrever qualquer coisa para qualquer pessoa, o que fatalmente resulta em textos sem sentido, sem argumentação e sem autoria, mais ou menos respondendo à hipótese de uma moral equivocada presente na escola e especificamente no ensino de produção textual (BERNARDO, 1991).

Lemos analisa igualmente textos de vestibulandos:

o candidato ao vestibular enfrentaria a tarefa de elaboração como um conjunto de operações de preenchimento de uma estrutura previamente dada, ou inferida de textos-modelo. Essa estrutura-esquema ou arcabouço - definível como uma articulação de posições vazias - seria preenchida com asserções genéricas ou específicas, construídas a partir das evocações que o título da redação possa sugerir. (LEMOS, 1977, p. 62). 
De fato, do ponto de vista discursivo, a estratégia desses alunos seria de "preenchimento". Mas nossa hipótese emerge outro critério, numa inversão do vetor de análise. Para nós, do ponto de vista sintático-semântico, a estratégia é de "esvaziamento".

Por fim, gostaríamos de frisar um último aspecto do documento oficial em preparação pelo Ministério da Educação e Cultura (MEC). Começamos com ele e agora vamos terminar com ele também. Só que agora é para o bem.

A BNCC de Língua Portuguesa organiza sua apresentação prospectiva entre Eixos (oralidade, leitura, escrita, norma culta), Campos (literário, político, investigativo), e respectivas Unidades curriculares (BRASIL, 2016). O que chama a atenção para o Campo investigativo é que a proposta é efetivamente desenvolver nos alunos reflexão sobre a língua, possibilitando ao espaço de sala de aula um ambiente de laboratório linguístico: "O campo investigativo garante ao estudante o acesso ao conhecimento (...), possibilitando-lhe desenvolver capacidades de investigação, de produção e de divulgação de conhecimentos”. (BRASIL, 2016, p. 511).

Ilari (1997, p. 15) já argumentava a favor dessa postura científica sobre a língua em sala de aula, sobretudo na formação do professor de Letras: ${ }^{5}$

\footnotetext{
Idealmente, o estudante e o professor devem adotar em relação aos fatos a mesma atitude do cientista natural: levantar hipóteses intuitivas, dar a essas hipóteses uma formulação exata, inferir suas consequências e confrontá-las com os fatos, para uma confirmação ou uma refutação.
}

Transpondo isso para o trabalho com texto, a análise linguística, mediada pelo professor, levaria o aluno a traçar hipóteses sobre a língua em função de sua produção textual.

Nesse sentido, a semântica e a sintaxe desenvolvidas aqui como pistas à análise argumentativa podem talvez sinalizar um caminho 'investigativo' aos nossos alunos, agora protocientistas.

\section{Referências}

ADAM, J. M. Linguistique textuelle - des genres de discours aux textes. Paris: Nathan Université, 2004.

. A linguística textual - introdução à análise textual dos discursos. Tradução de Maria das Graças Soares Rodrigues, João Gomes da Silva Neto, Luís Passeggi e Eulália Vera Lúcia Fraga Leurquin. São Paulo: Cortez, 2008.

BAKHTIN, Mikhail. Estética da criação verbal. Tradução de Maria Ermantina Galvão G. Pereira. São Paulo: Martins Fontes, 1992.

\footnotetext{
$5 \mathrm{O}$ argumento da analogia entre linguistas e cientistas naturais também é recuperado em Oliveira \& Quarezemin (2016) e Perini (2002; 2004, dentre outros).
} 
BEAUGRANDE, R. A.; DRESSLER, W. U. Introduction to text linguistics. London: Longman, 1983.

BERNARDO, G. Redação Inquieta. 4. ed. Rio de Janeiro: Globo, 1991.

BRASIL. Ministério da Educação. Base Nacional Comum Curricular. Proposta preliminar. Segunda versão revista. Brasília: MEC, 2016.

CANÇADO, M. Manual de Semântica. São Paulo: Contexto, 2012.

CHAROLLES, M. Introdução aos problemas da coerência nos textos. In: GONÇALVEZ, C. (Org.). O texto: leitura e escrita. Campinas: Pontes, 1989, p. 39-90.

COSTA VAL, M. da G. Redação e textualidade. São Paulo: Martins Fontes, 1991.

DOLZ, J. Learning argumentative capacities - A study of the effects of a systematic and intensive teaching of argumentative discourse in 11-12 year old children. Argumentation, v. 10, n. 2, p. 227-251, 1996.

FIORIN, J. L. Argumentação. São Paulo: Contexto, 2015.

GERALDI, J. W. Portos de Passagem. São Paulo: Martins Fontes, 1991.

ILARI, R. A lingüística e o ensino de língua portuguesa. São Paulo: Martins Fontes, 1997.

KENNEDY, C; MCNALLY, L. Scale Structure and the Semantic Typology of Gradable Predicates. Language, v. 81, n. 2, p. 345-381, 2005.

KOERNER, E. F. K.; ASHER, R. E. Concise History of the Language Sciences - from the Sumerians to the cognitivists. Cambridge: Pergamon, 1995.

LEMOS, C. de. Redações de vestibular: algumas estratégias. Cadernos de Pesquisa da Fundação Carlos Chagas, São Paulo, n. 23, p. 60-73, dez. 1977.

LYONS, J. Semântica - volume 1. Trad. Wanda Ramos. Lisboa: Editorial Presença/ Martins Fontes, 1977.

MIOTO, C.; FIGUEIREDO SILVA, M. C.; LOPES, R. E. V. Novo manual de sintaxe. 2. ed. Florianópolis: Insular, 2005.

MÜLLER, A. L. A expressão de genericidade nas línguas naturais. In: Müller et. al. (Org.). Semântica Formal. São Paulo: Contexto, 2003, p. 153-172.

OLIVEIRA, R. P. de; PERUCHI MEZARI, M. (Org.). Nominais nus - um olhar através das línguas. Campinas: Mercado das Letras, 2012.

OLIVEIRA, R. P. de; QUAREZEMIN, S. Gramáticas na escola. Petrópolis: Vozes, 2016. PÉCORA, A. Problemas de redação. São Paulo: Martins Fontes, 1992.

PERINI, M. A. Sofrendo a gramática. São Paulo: Ática, 2002. . A língua do Brasil amanhã e outros mistérios. São Paulo: Parábola, 2004.

PINKER, S. Learnability and cognition - the acquisition of argument structure. Cambridge: MIT Press, 1989. 
POSSENTI, S. Indícios de autoria. Perspectiva, Florianópolis, v. 20, n. 1, p. 105-124, 2002. RAPOSO, E. Teoria da gramática: a faculdade da linguagem. Lisboa: Caminho, 1992.

REBOUL, O. Introdução à retórica. Tradução Ivone Castilho. São Paulo: Martins Fontes, 1998.

ROBINS, R. H. Pequena história da lingüística. Tradução de Luiz M. M. de Barros. Rio de Janeiro: Ao Livro Técnico, 1983.

SAEED, J. Semantics. 2. ed. Blackwell Publishing, 2005.

TOULMIN, S. E. Os usos do argumento. Tradução de Reinaldo Guarany. São Paulo: Martins Fontes, 2006.

Data de submissão: 31/07/2017

Data de aceite: $17 / 10 / 2017$ 